\title{
KINERJA LEMARI PENDINGIN ALAMI YANG DIGUNAKAN SESUAI KONDISI CUACA DI KOTA MEDAN
}

\author{
Tulus B. Sitorus1,2, Tekad Sitepu1, Farida Ariani1 \\ 1Departemen Teknik Mesin, Universitas Sumatera Utara \\ 2PUI Energi Berkelanjutan \& Biomaterial, Universitas Sumatera Utara \\ *Email: tburhanudin@yahoo.com
}

\begin{abstract}
ABSTRAC
One application in a direct evaporative cooling system was a natural cooler. The advantages of this system were not using the electrical energy and so far also environmentally. This research aims to obtain a performance analysis of the natural cooler as a store for vegetables and fruits in Medan city. The materials for natural cooler consists of teak wood and gunny. The experiments were conducted during seven days in the open air, which were exposed to the solar radiation. The parameter measurement on the weather was using HOBO devices and to record the temperature changes for vegetables or even fruits is using its acquisition data. The results showed that the maximum efficiency of the natural cooler could be obtained for $43.79 \%$ in the average air temperature of $30.51{ }^{\circ} \mathrm{C}$, the air humidity average is $85.12 \%$ with average solar radiation of $183.98 \mathrm{~W} / \mathrm{m}^{2}$. Experimental data were showing that the condition of freshness on vegetables or even on fruits was heavily influenced by weather conditions.
\end{abstract}

\section{Kata Kunci: Hasil Belajar, strategi pembelajaran Problem Based Learning (PBL), strategi Pembelajaran Ekspositori}

\section{PENDAHULUAN}

Berdasarkan data pengelolaan energi nasional Indonesia [1] bahwa penggunaan bahan bakar minyak telah mencapai lebih dari $60 \%$ dari keseluruhan konsumsi energi di tahun 2005. Hal ini terus meningkat setiap tahun seiring pertumbuhan penduduk dan pembangunan ekonomi. Pada saat ini konsumsi bahan bakar dan energi cukup berdampak pada kondisi ekonomi nasional. Saat ini diperlukan untuk memikirkan teknologi ramah lingkungan yang dapat mengurangi konsumsi energi terutama bahan bakar dan energi listrik. Salah satu jenis teknologi yang masih berguna bagi manusia adalah mesin atau lemari pendingin. Lemari pendingin alami merupakan alat yang bekerja hampir sama prinsipnya dengan mesin kalor yang menggunakan untuk menjaga agar temperatur benda atau sistem lebih rendah dari temperature lingkungan. Di daerah khatulistiwa seperti Indonesia, sistem pendingin dengan menggunakan refrijeran masih dibutuhkan karena sangat murah dan efektif. Menurut [2, 3], Indonesia selalu terpapar sinar matahari selama 10-12 jam setiap hari dan diperkirakan intensitas ratarata radiasi matahari berkisar $4,8 \mathrm{kWh} / \mathrm{m}^{2}$. Dalam kajian ini, sistem pendingin yang diuji tanpa menggunakan energi listrik atau mekanik sehingga disebut sebagai dengan lemari pendingin alami. Tujuan penelitian ini adalah untuk mendapatkan kinerja analisis lemari pendingin alami yang diuji dengan menggunakan air sebagai media pendinginan. Meskipun lemari pendingin alami untuk sayuran dan buah sudah ada diterapkan, namun penelitian mengenai teknologi sederhana ini masih sangat dipublikasikan.

\subsection{Prinsip kerja lemari pendingin alami}

Proses kerja yang terjadi pada lemari pendingin alami merupakan peristiwa pendinginan dengan cara evaporasi (evaporative cooling). Pendinginan dengan cara evaporasi merupakan suatu fenomena fisik dimana proses penguapan cairan ke dalam udara lingkungan untuk mendinginkan suatu benda yang bersentuhan dengannya. Kondisi ini mengakibatkan permukaan dari benda menjadi lebih dingin saat air menguap 
darinya karena air membutuhkan panas untuk dapat berubah fasa dari cair menjadi uap [4]. Atau dapat juga dikatakan suatu proses perpindahan panas dan massa yang menggunakan evaporasi air untuk pendinginan udara, dimana jumlah panas yang ditransfer dari udara ke air cukup besar sehingga temperatur udara menjadi menurun $[5,6]$. Secara umum, sistem pendinginan dengan cara evaporasi diklasifikasikan menjadi 3 jenis yaitu pendinginan evaporasi secara langsung (direct evaporative cooling), pendinginan evaporasi secara tidak langsung (indirect evaporative cooling) dan sistem gabungan evaporasi langsung dan tidak langsung (combined system) [7]. Aplikasi dari sistem pendingin evaporasi tak langsung adalah pemanasan, ventilasi, HVAC untuk gedung dan pusat perbelanjaan. Salah satu aplikasi dari sistem pendinginan evaporasi langsung adalah lemari pendingin alami untuk menyimpan sayuran dan buah-buahan [8]. Berdasarkan laporan penelitian bahwa untuk pengawetan sayuran dan buah-buahan diperlukan temperatur udara rendah dan kelembaban udara tinggi sehingga akan memperlambat aktivitas patologis yang umumnya berada di dataran yang tinggi [9]. Dapat dikatakan bahwa sistem pendinginan alami ini sangat dipengaruhi oleh kondisi cuaca diantaranya temperatur dan kelembaban udara sehingga sangat sesuai diaplikasikan pada daerah subtropis dan tropis $[10,11]$. Secara umum, lemari pendingin alami menggunakan kain goni sebagai wadah atau tempat berkumpulnya air yang digunakan sebagai media pendingin.

\subsection{Kinerja Lemari Pendingin Alami}

Kinerja lemari pendingin alami dapat ditentukan dengan meninjau proses perpindahan panas yang terjadi di sekitar lemari pendingin alami tersebut. Besarnya perpindahan panas konduksi (watt) yang terjadi pada dinding lemari pendingin alami dapat dihitung dari persamaan [12]:

$$
\mathrm{Q}_{\mathrm{kond}}=\mathrm{kA} \frac{\Delta \mathrm{T}}{\mathrm{L}}
$$

dimana $\mathrm{k}$ adalah konduktivitas termal material (W/m .K), A adalah luas penampang perpindahan panas konduksi $\left(\mathrm{m}^{2}\right), \Delta \mathrm{T}$ adalah perbedaan temperatur yang terjadi antara temperatur permukaan dinding lemari pendingin dengan temperatur udara lingkungan $\left({ }^{\circ} \mathrm{C}\right)$ dan $\mathrm{L}$ adalah tebal dinding lemari pendingin $(\mathrm{m})$.

Sedangkan besarnya proses perpindahan panas konveksi (watt) yang terjadi pada dinding lemari pendingin alami adalah

$\mathrm{Q}_{\mathrm{konv}}=\mathrm{hA}\left(\mathrm{T}_{\mathrm{s}}-\mathrm{T}_{\infty}\right)$

diimana $h$ adalah nilai koefisien perpindahan panas konveksi $\left(\mathrm{W} / \mathrm{m}^{2} \mathrm{~K}\right)$, A adalah luas penampang perpindahan panas konveksi $\left(\mathrm{m}^{2}\right)$ dan $\Delta \mathrm{T}$ adalah perbedaan temperatur yang terjadi antara temperatur permukaan dinding lemari pendingin dengan temperatur udara lingkungan $\left({ }^{\circ} \mathrm{C}\right)$.

Dan besarnya proses perpindahan panas radiasi (watt) yang terjadi pada dinding lemari pendingin alami adalah :

$$
\mathrm{Q}_{\mathrm{rad}}=\varepsilon \sigma \mathrm{A}\left(\mathrm{T}_{\mathrm{s}}-\mathrm{T}_{\infty}\right)
$$

dimana $\varepsilon$ adalah emisivitas material yang digunakan (untuk kayu 0,88 dan untuk kain goni 0,72), A adalah luas penampang perpindahan panas radiasi $\left(\mathrm{m}^{2}\right), \sigma$ adalah konstanta Stefan Boltzman $\left(5,67 \times 10^{-8}\right.$ $\left.\mathrm{W} / \mathrm{m}^{-2} \mathrm{~K}^{-4}\right), \mathrm{T}_{\mathrm{s}}$ adalah temperatur dinding lemari pendingin $\left({ }^{\circ} \mathrm{C}\right)$ dan $\mathrm{T}_{\infty}$ adalah temperatur udara di sekitar lemari pendingin $\left({ }^{\circ} \mathrm{C}\right)$.

Berdasarkan uraian di atas maka besarnya perpindahan panas total dari lemari pendingin alami diperoleh dari penguapan yang terjadi pada dinding lemari pendingin yang merupakan gabungan dari proses perpindahan panas secara konveksi alamiah, konduksi dan radiasi:

$$
\mathrm{Q}_{\text {total }}=\mathrm{Q}_{\mathrm{kond}}+\mathrm{Q}_{\mathrm{konv}}+\mathrm{Q}_{\mathrm{rad}}
$$

Sehingga besarnya efisiensi lemari pendingin alami dapat ditentukan dari persamaan:

$$
\eta=\frac{Q_{S}+Q_{L}}{Q_{\text {total }}}
$$


dimana $\mathrm{Q}_{\mathrm{S}}$ adalah besarnya kalor sensibel udara (watt) dan $\mathrm{Q}_{\mathrm{L}}$ adalah besarnya kalor laten udara (watt).

\section{METODE PENELITIAN}

\subsection{Bahan}

Bahan untuk pembuatan lemari pendingin alami penelitian ini adalah kayu jati dengan ketebalan $3,5 \mathrm{~cm}$ dengan pertimbangan kekuatan material cukup baik, tahan terhadap air dan rayap serta relatif mudah didapat. Dimensi lemari pendingin alami adalah $490 \mathrm{~mm}$ (lebar) x $530 \mathrm{~mm}$ (panjang) x $1550 \mathrm{~mm}$ (tinggi).

Kain goni berwarna putih digunakan sebagai penutup dinding lemari pendingin alami dengan ketebalan $1 \mathrm{~mm}$ yang digunakan pada sisi kanan, kiri, belakang dan depan. Untuk dinding atas dan dinding bawah di bawah rak, digunakan kayu lapis dengan ketebalan $1 \mathrm{~cm}$ agar tahan lebih tahan terhadap air. Air sebagai media pendingin memiliki temperatur tidak lebih dari $25^{\circ} \mathrm{C}$. Objek yang ditempatkan di dalam lemari pendingin alami adalah sayuran dan buah-buahan. Spesifikasi utama dari lemari pendingin alami yang digunakan ditunjukkan pada tabel 1. Sedangkan foto lemari pendingin alami yang diuji ditunjukkan pada gambar 1.

Tabel 1. Spesifikasi lemari pendingin alami

\begin{tabular}{|c|c|c|}
\hline No & Data & Keterangan \\
\hline 1 & Rangka & $\begin{array}{l}\text { Kayu jati, } \mathrm{k}=0,12 \mathrm{~W} / \mathrm{m} \\
\mathrm{K} \text { pada } 27^{\circ} \mathrm{C}\end{array}$ \\
\hline 2 & Dinding & $\begin{array}{l}\text { Kain goni, } \mathrm{k}=0,06 \mathrm{~W} / \mathrm{m} \\
\mathrm{K} \text { pada } 27^{\circ} \mathrm{C}\end{array}$ \\
\hline 3 & $\begin{array}{l}\text { Media } \\
\text { pendingin }\end{array}$ & 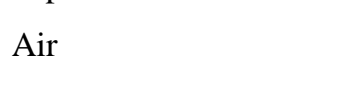 \\
\hline 4 & Pipa & Tembaga $(\varnothing=8 \mathrm{~mm})$ \\
\hline 5 & Tangki air & 2 Tangki (volume 8 liter) \\
\hline 6 & $\begin{array}{l}\text { Objek yang } \\
\text { didinginkan }\end{array}$ & Sayur dan buah \\
\hline
\end{tabular}

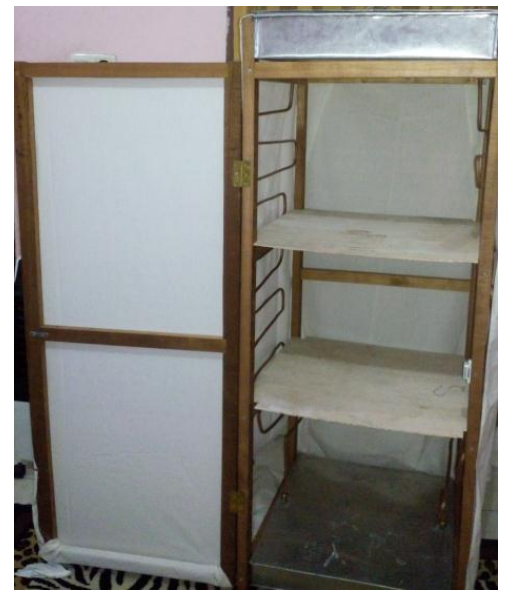

Gambar 1 Foto lemari pendingin alami yang dirakit

\subsection{Skema Eksperimental}

Lemari pendingin alami terhubung ke sistem akuisisi data, agilent 3497A melalui termokopel. Enam termokopel digunakan dalam eksperimen yaitu tiga untuk objek yang didinginkan dan tiga pada lemari pendingin alami. Perubahan temperatur diukur dengan menggunakan termokopel tipe $\mathrm{J}$ dengan akurasi $\pm 0,4 \%$. Alat ukur cuaca HOBO digunakan untuk mencatat kondisi cuaca yang meliputi intensitas radiasi matahari (pyranometer dengan akurasi \pm $5 \%$ ), temperatur lingkungan (akurasi $\pm 0,2^{\circ} \mathrm{C}$ ), kelembaban relatif (akurasi $\pm 2.5 \%$ ) dan kecepatan angin (akurasi $\pm 3 \%$ ). Pada penelitian ini, waktu Indonesia Barat atau WIB digunakan di kota Medan untuk waktu setempat. Pengujian dilakukan selama tujuh hari berturut-turut pada bulan Mei 2017 di Laboratorium Energi Matahari, Universitas Sumatera Utara di kota Medan dengan koordinat geografis $3^{\circ} 35^{\prime}$ Lintang Utara, $98^{\circ} 40^{\prime}$ Bujur Timur. Gambar 2 menunjukkan skema lemari pendingin alami dan sistem pengukuran yang dilakukan.

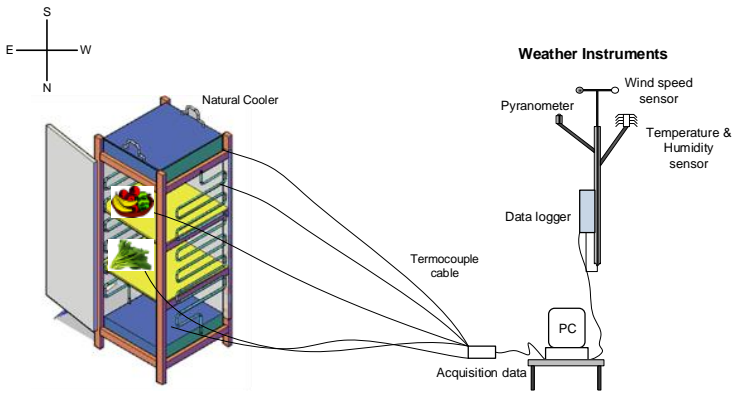

Gambar 2 Skema eksperimental penelitian 


\section{HASIL DAN PEMBAHASAN}

\subsection{Kondisi Cuaca}

Diperlukan pengamatan terhadap kondisi cuaca karena pengujian dilakukan pada kondisi udara terbuka yang terpapar radiasi matahari. Proses pengukuran kondisi cuaca dilakukan selama 24 jam untuk tujuh hari dengan proses pengukuran dilakukan setiap rentang satu menit.

Tabel 2. Kondisi cuaca selama pengujian

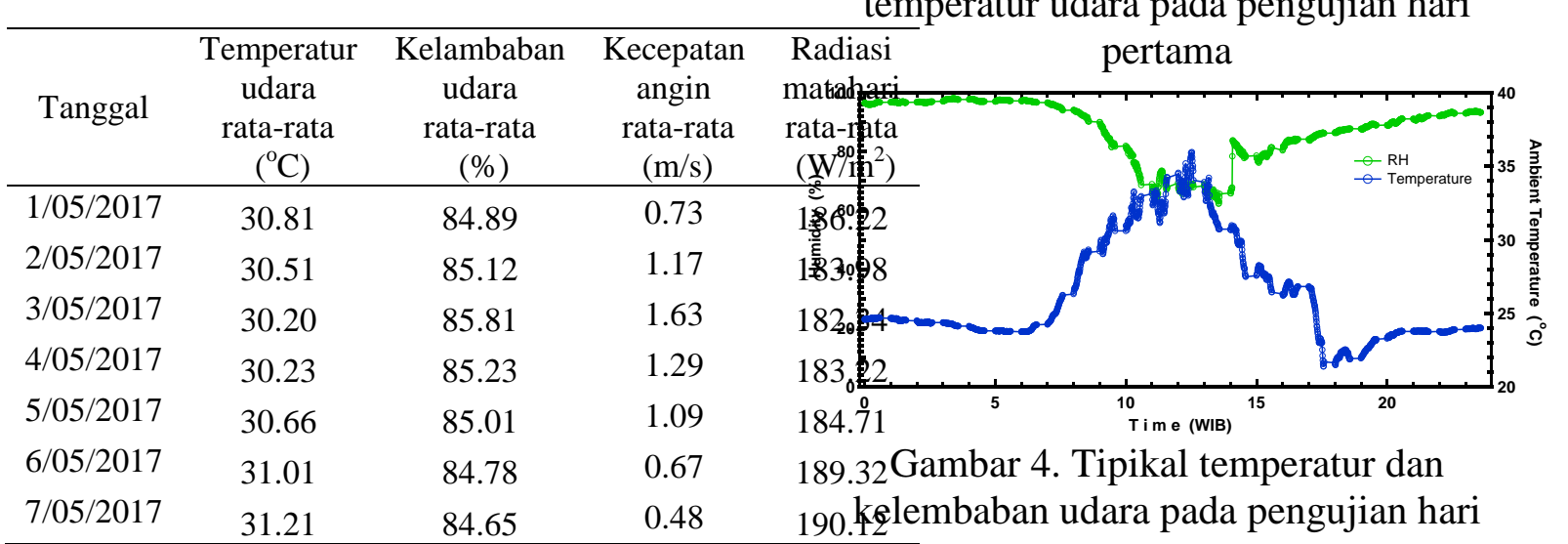

Tabel 2 menunjukkan parameter kondisi cuaca selama proses pengujian yang meliputi temperatur dan kelembaban udara, kecepatan angin dan radiasi matahari yang bervariasi. Gambar 3 menunjukkan tipikal radiasi matahari dan temperatur udara pada pengujian hari pertama. Gambar 4 menunjukkan korelasi signifikan antara perubahan temperatur udara dengan kelembaban udara yang berkorelasi dengan radiasi matahari yang terjadi pada lokasi pengujian. Data eksperimental menunjukkan bahwa radiasi matahari mulai terdeteksi mulai pukul 06.20 WIB hingga 18.25 WIB. Selama pengujian untuk tujuh hari, diperoleh radiasi matahari rata-rata $186.22 \mathrm{~W} / \mathrm{m}^{2}$, temperatur udara rata-rata $30.81^{\circ} \mathrm{C}$ dan kelembaban udara rata-rata $84.89 \%$.

\subsection{Kinerja Lemari Pendingin Alami}

Pengukuran perubahan temperatur di lemari pendingin alami dilakukan dengan menempatkan sensor termokopel pada lemari pendingin di sisi atas, kanan, kiri, atas, bawah serta sayur maupun buah. Lemari pendingin alami diuji dengan kondisi dinding belakang menghadap arah timur.

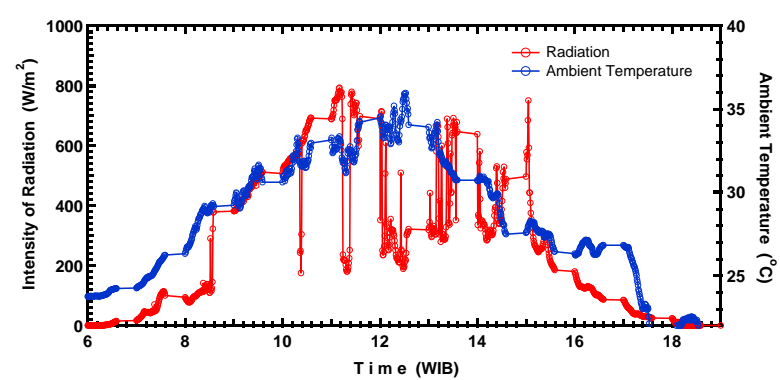

Gambar 3. Tipikal radiasi matahari dan temperatur udara pada pengujian hari

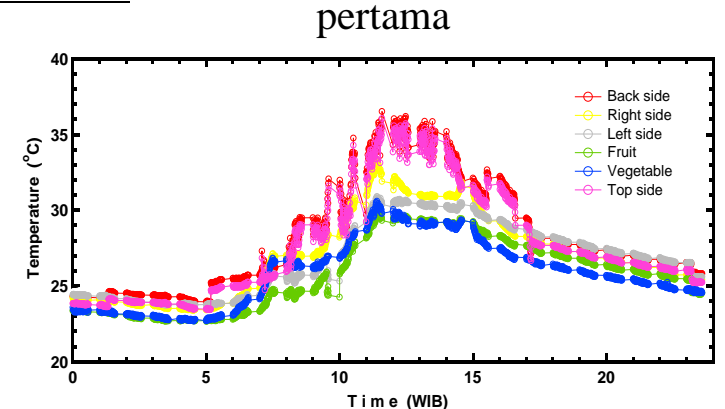

Gambar 5. Tipikal temperatur komponen pada pengujian hari pertama

Gambar 5 menunjukkan fluktuasi temperatur setiap komponen yang diukur untuk pengujian hari pertama. Hal ini berkorelasi dengan perubahan kondisi cuaca yang terjadi setiap saat. Besarnya temperatur masing-masing komponen meningkat mulai pukul 07.00 WIB pagi dan mencapai temperatur maksimum pada pukul 12.00 WIB - 14.00 WIB yang seiring dengan meningkatnya radiasi matahari dan temperatur lingkungan. Selama pengujian, temperatur maksimum sayuran dan buah berkisar antara $34^{\circ} \mathrm{C}-35^{\circ} \mathrm{C}$. Temperatur minimum sayuran dan buah berkisar $22^{\circ} \mathrm{C}$ $23^{\circ} \mathrm{C}$ yang terjadi antara pukul $04.00 \mathrm{WIB}$ - 
05.00 WIB. Secara umum, temperatur di dinding belakang lebih tinggi dari dinding yang lain karena dinding belakang menghadap langsung ke arah timur atau matahari terbit sehingga menyerap lebih banyak radiasi matahari. Untuk menjaga agar sayuran dan buah tidak cepat layu maka digunakan air sebagai media pendingin yang dialirkan di dalam pipa dan ditempatkan di sekitar dinding lemari pendingin alami. Dari hasil perhitungan dengan memperhitungkan massa sayur dan buah di dalam lemari pendingin alami dan proses perpindahan panas yang terjadi maka volume air yang dibutuhkan untuk proses pendinginan berkisar 8 liter di dalam 2 tangki. Temperatur udara rata-rata berkisar $30,66^{\circ} \mathrm{C}$, kelembaban udara rata-rata $85,07 \%$ dan radiasi matahari rata-rata $185,70 \mathrm{~W} / \mathrm{m}^{2}$. Air digunakan untuk mencegah panas dari udara luar ke dalam lemari pendingin alami dan menyerap panas dari buah-buahan dan sayuran. Saat mengalami proses pengeringan, panas dari lingkungan sekitarnya yang masuk ke lemari pendingin alami dan dihasilkan oleh buah dan sayuran tidak bisa diserap oleh kain goni. Hal ini bisa mengakibatkan sayuran dan buah-buahan di dalam pendingin secara alami akan cepat layu. Kondisi fisik sayuran dan buah-buahan selama pengujian dapat dilihat pada gambar 6 dan 7. Tampak bahwa kondisi sayuran dan buah-buahan mulai menurun atau layu pada hari ketujuh.

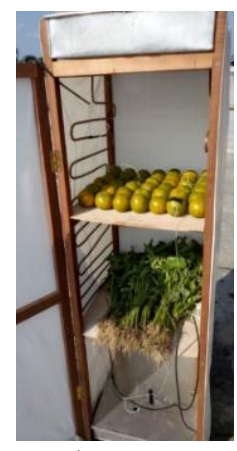

Hari pertama

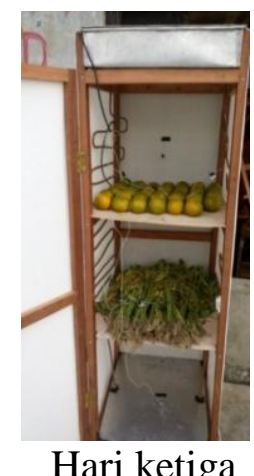

Hari ketiga

Gambar 6. Kondisi sayur dan buah pada hari pertama dan ketiga

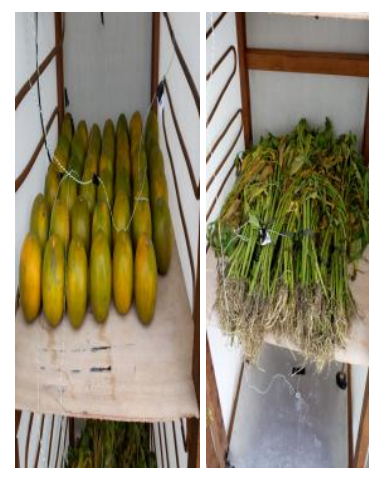

Hari kelima

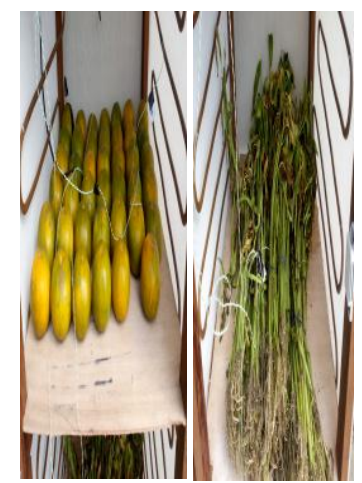

Hari ketujuh
Gambar 7. Kondisi sayur dan buah pada hari kelima dan ketujuh

Tabel 3. Efisiensi lemari pendingin alami selama pengujian

\begin{tabular}{ccccc}
\hline Hari & $\begin{array}{c}\mathrm{Q}_{\mathrm{S}} \\
(\mathrm{W})\end{array}$ & $\begin{array}{c}\mathrm{Q}_{\mathrm{L}} \\
(\mathrm{W})\end{array}$ & $\begin{array}{c}\mathrm{Q}_{\text {total }} \\
(\mathrm{W})\end{array}$ & $\eta_{\mathrm{nc}}$ \\
\hline 1 & 0.344 & 31.510 & 79.615 & $40.01 \%$ \\
2 & 0.306 & 30.679 & 70.755 & $43.79 \%$ \\
3 & 0.344 & 30.143 & 79.120 & $38.53 \%$ \\
4 & 0.348 & 29.853 & 79.937 & $37.78 \%$ \\
5 & 0.335 & 31.096 & 77.206 & $40.71 \%$ \\
6 & 0.364 & 32.100 & 84.772 & $38.30 \%$ \\
7 & 0.373 & 32.682 & 87.121 & $37.94 \%$ \\
\hline
\end{tabular}

Tabel 3 menunjukkan bahwa efisiensi lemari pendingin alami selama pengujian. Nilai maksimum efisiensi lemari pendingin alami yang diperoleh selama pengujian adalah $43,79 \%$ pada hari kedua. Efisiensi maksimum lemari pendingin alami diperoleh saat kondisi rata-rata udara $30.51{ }^{\circ} \mathrm{C}$, kelembaban udara $85,12 \%$ dan radiasi matahari rata-rata $183.98 \mathrm{~W} / \mathrm{m}^{2}$.

Besarnya nilai efisiensi lemari pendingin alami berfluktuasi setiap hari. Berdasarkan data dari hasil pengukuran dan perhitungan diperoleh bahwa efisiensi lemari pendingin alami dipengaruhi oleh proses perpindahan panas yang terjadi di lemari pendingin alami secara radiasi, konduksi, konveksi dan panas dari sayur dan buah serta variasi cuaca selama pengujian dilakukan 
1.7. Korelasi kondisi cuaca dengan kinerja lemari pendingin alami

Korelasi antara kondisi cuaca dengan efisiensi lemari pendingin alami telah dilakukan. Data cuaca yang digunakan selama tujuh hari pengujian. Tabel 4 menampilkan parameter kondisi cuaca yang berkorelasi secara signifikan terhadap efisiensi lemari pendingin alami. Dengan menggunakan fungsi analisis regresi berganda diperoleh koefisien determinasi sebesar 0,86 yang berarti bahwa pengaruh kondisi cuaca terhadap efisiensi lemari pendingin alami yang diuji berkisar $86 \%$.

Tabel 4. Korelasi kondisi cuaca terhadap efisiensi lemari pendingin alami

\begin{tabular}{|l|c|c|c|c|c|}
\hline & A & B & C & D & E \\
\hline A & 1 & & & & \\
\hline B & -0.95 & 1 & & & \\
\hline C & 0.66 & -0.69 & 1 & & \\
\hline D & -0.90 & 0.83 & -0.68 & 1 & \\
\hline E & 0.68 & -0.58 & -0.73 & -0.55 & 1 \\
\hline
\end{tabular}

Keterangan:

$\mathrm{A}=$ Temperatur udara

$\mathrm{B}=$ Kelembaban udara

$\mathrm{C}=$ Radiasi matahari

$\mathrm{D}=$ Kecepatan angin

$\mathrm{E}=$ Efisiensi Lemari pendingin

\section{KESIMPULAN}

Lemari pendingin alami tanpa menggunakan listrik dan ramah lingkungan telah berhasil dibuat dan diuji kinerjanya. Proses pengujian dilakukan di udara terbuka dengan berbagai kondisi cuaca. Pengamatan dilakukan terhadap kondisi cuaca yang meliputi temperatur lingkungan, kelembaban udara, dan radiasi matahari. Dalam penelitian ini, diperoleh temperatur rata-rata sayuran dan buah berada pada kisaran $24,29^{\circ} \mathrm{C}$ selama pengujian. Berdasarkan data eksperimental dan perhitungan diperoleh efisiensi maksimum lemari pendingin alami 43,79\%. Berdasarkan analisa statistik, diperoleh korelasi pengaruh kondisi cuaca terhadap kinerja lemari pendingin alam yang diuji berkisar $86 \%$. Pada penelitian selanjutnya akan difokuskan pada peningkatan efisiensi lemari pendingin alami sehingga lama kesegaran buah dan sayuran bisa bertahan lebih lama.

\section{DAFTAR PUSTAKA}

Buku Putih Penelitian 2006 Pengembangan dan Penerapan Ilmu Pengetahuan dan Teknologi Bidang Sumber Energi Baru dan Terbarukan untuk Mendukung Keamanan Ketersediaan Energi Tahun 2025. Kemenristek, Jakarta.

Tulus B. Sitorus, Farel H. Napitupulu, Himsar Ambarita 2016 Experimental Study of Solar Refrigerator System Using Activated Alumina and Methanol Adsorption Pair, International Journal of Technology, IJTech Journal, pp. 910-922, Vol. 7 Issue 5, ISSN 2086-9614.

Meita Rumbayan, Ken Nagasaka, 2012 Solar Irradiation Estimation With Neural Network Method Using Meteorological Data In Indonesia International Journal of Technology 2: pp.110-120, ISSN 2086-9614.

Ndukwu C.,N, S. I. Manuwa 2014 Review of research and application of evaporative cooling in preservation of fresh agricultural produce. Int J Agric \& Biol Eng. Vol. 7 No.5.

Amer, R. Boukhanouf, and H. Ibrahim 2015 A Review of Evaporative Cooling Technologies. International Journal of Environmental Science and Development. Vol. 6, No. 2.

Xuan M.,Y, F. Xiao, X. F. Niu, X. Huang, and S. W. Wang 2012 Research and application of evaporative cooling in China: A review (I) - research. Renewable and Sustainable Energy Reviews. vol. 16, pp. 3535-3546. 
Duan et al. 2012 Indirect evaporative cooling: Past, present and future potentials Renewable and Sustainable Energy Reviews. vol. 16, pp. 6823 6850 .

Porumba B., P. Ungureşana, L.F. Tutunarua, A. Șerban,M.Bălana 2016 A review of indirect evaporative cooling technology. Energy Procedia 85 pp. $461-471$.

Adebisi O W, Igbeka J C, Olurin T O. 2009 Performance evaluation of absorbent materials in evaporative cooling system for the storage of fruits and vegetables. International Journal of Food Engineering. 2009; 5(3): pp.1-15.

T. Pistochini and M. Modera 2011 Water-use efficiency for alternative cooling technologies in arid climates. Energy and Buildings. vol. 43. pp. 631-638.

Isaac F. Odesola, Onwuka Onyebuchi 2009 A Review of Porous Evaporative Cooling for the Preservation of Fruits and Vegetables. The Pacific Journal of Science and Technology. Volume 10. No. 2.

Çengel A.,Y 2003 Fundamentals of Thermal Fluids Science : A Practical Approach. McGraw-Hill. 